\title{
Biosimilar switching and related medical liability.
}

\begin{abstract}
Unlike generics, biosimilars are similar, but not equivalent, to the reference biological medicinal product. Therefore, if a patient experiences an adverse event, or a loss of efficacy, when transitioned to a biosimilar, the distribution of medical liability will be different from the case of both the originator and generics. Moreover, the case of naïve patients is different from that of non-naïve patients. In the case of naïve patients, physicians make their choice from a range of medicinal products that pose the same risk, since it is not possible to know with any certainty the patients' response to each therapeutic option until they have taken the drug. If physicians, instead, switch to a biosimilar for a patient already in treatment with the originator, they are switching from an option where the individual response is known, to an option where it is unknown.
\end{abstract}

Given the evolving framework of biosimilar legislation, sharing choices with patients and obtaining their informed consent when switching to a biosimilar could represent an effective approach on the part of the prescribing physician. Moreover, a supranational database containing real-life data about patients in treatment with biological medicines, including information on the actual biological medicinal products administered, could complement the data obtained from clinical studies.

\section{Keywords}

Biosimilars, interchangeability, substitution, non-nä̈ve patients, informed consent, medical liability. 


\section{Introduction}

A biosimilar is a medicinal product that is highly similar, but not equivalent, to an already approved biological medicine, so-called originator [1,2]. Therefore, if a patient experiences an adverse event, or a loss of efficacy, the distribution of liability will be different from the case of both the originator and generics. When an adverse event to a medicinal product is experienced by a patient, we can imagine that a chain liability starts, potentially implicating the health professionals involved in the prescription, dispensing and administration of the product on the one hand (professional liability), and the manufacturers and/or Marketing Authorization holder on the other (products liability).

\section{Products liability}

According to US jurisprudence, a medicinal product is defective if, at the time of sale: (1) it contains a manufacturing defect (i.e. the product departs from its intended design), or (2) it is not reasonably safe due to defective design, or (3) it is not reasonably safe due to inadequate instructions or warnings (failure to warn) [3].

As for manufacturing defects, it is difficult to decide when biological products departs from their intended design, due to their inherent variability. Moreover, the complexity of the manufacturing process of biological medicines blurs the boundary between manufacturing and design defects. Therefore, the Marketing Authorization holder of a biosimilar may hold potential liability for both manufacturing and design defects, unlike the case of generics, where those boundaries are clear.

A potential failure to warn liability is not usually ascribable to the generic's Marketing Authorization holder, as confirmed by the US Supreme Court in 2011 in Pliva v. Mensing (564 U.S. 
604), since the generic product bears the same labelling as the originator [4]. In the case of biosimilars, instead, the label is not necessarily identical, therefore the Marketing Authorization holder of the biosimilar may be considered responsible if the label fails to provide adequate warning.

\section{Professional liability}

The publication of the results from NOR-SWITCH, a randomised, non-inferiority, double-blind, phase 4 trial addressing the issue of switching from the originator infliximab to a biosimilar in stable patients [5], finally shed some light on a highly debated topic. The conclusions of the study can be seen as reassuring for prescribing physicians, at least in the case of infliximab. However, the issue of medical liability associated with the switch from the originator to a biosimilar is still far from being explored.

Of the possible causes of medical liability, the aspects related to interchangeability and substitution play a crucial role in the case of biological medicines, since other issues - such as diagnosis, prescription or dispensing errors - concern other medicinal products, as well.

\section{Interchangeability and substitution}

Interchangeability is a scientific concept, related to intrinsic drug characteristics, which follows from therapeutic equivalence $[2,6]$. The term 'substitution' instead can have different meanings. It could mean either a substitution that occurs under the physician's responsibility, or automatic substitution. Automatic substitution occurs at the dispensing level, without the physician's explicit prior consent, and it can be introduced by local authorities on the basis of interchangeability. In the case of biosimilars, however, it is usually not allowed [7]. 
Substitution performed by the prescribing physician is always possible, though it can take three forms with different implications: (1) the prescription of a biosimilar to nä̈ve patients, (2) the switch from the originator to a biosimilar, (3) the prescription of a biosimilar, to nä̈ve or non-nä̈ve patients, due to payer's policies (non-medical switching or constrained prescription).

\section{Potential sources of professional liability}

In the case of naïve patients, physicians make their choice from a range of medicinal products that pose the same risk, since it is not possible to know with any certainty the patients' response to each therapeutic option until they have taken the drug. If physicians, instead, switch to a biosimilar for a patient already in treatment with the originator, they are switching from an option where the individual response is known, to an option where it is unknown. Indeed, given that the production of biosimilars entails a variation in the manufacturing process compared to the originator, the use of biosimilars can lead to an exposure to different risks for the patient, even though the comparability exercise performed to obtain the Marketing Authorization is designed to demonstrate that the biosimilar has the same quality, safety and efficacy as the originator. Even when they are produced by the same manufacturer, all biopharmaceuticals show an inherent variability. However, the product resulting from batch-to-batch variability should not be considered a biosimilar, from a regulatory point of view, since the manufacturer has all the data needed to keep the production within accepted and pre-defined limits. [2].

When the prescription of a biosimilar arises from payer's binding policies, it is not substitution in the proper sense, and, if it constitutes an administrative limit to the prescriber's freedom, it is called 
differently, for example, non-medical switching or constrained prescription [7]. In this case, the issue of liability is more complex and the outcome of potential litigations is still very uncertain.

Nonetheless, where there is no real obligation to switch, but only a "recommendation" (think of administrative directives within the organization that the physician belongs to), or a "bureaucratic" limitation that is non-binding for the physician (think of a hospital medicines handbook which contains a more limited list of medicines compared to the national handbook), the physician would be the only person responsible for the therapeutic prescription. In most Countries, the physician could continue to choose - if necessary giving their justification and whenever they considered it necessary - the medicament which they considered the most suitable. Any economic grounds invoked to justify the different choice could even be considered conduct dictated by the desire to please the organization they belong to and its executives, for the purposes of possible personal recognition and professional advancement.

Likewise, any recommendations, guidelines, concept papers, or other documents issued by the regulatory authorities, given the emerging technical and scientific uncertainties regarding new medicaments, albeit not having any coercive power (since bereft of any sanctions), could tacitly affect the exercise of the medical choice due to their persuasive character. Thus, it could happen that the physician is induced to follow such indications even when their medical and scientific knowledge would lead them in reality to make different choices. In these cases, the responsibility for the therapeutic choice would always remain with the physician and, in the case of harm to the patient, the existence of the aforementioned documents would not be an absolving factor since they are not binding. 


\section{Biosimilar switching and informed consent}

Given the difficulties linked to clinical and scientific assessments, and the possible influence dictated by the difference in costs between originators and biosimilars, the informed consent of the patient becomes increasingly fundamental to certify that the therapeutic choice has been made through a process of sharing information between the physician and the patient. This process should take place with a view to collaboration and personalization, as part of which the physician provides the patient, in a correct, complete and understandable fashion, all the information needed to allow the latter to fully express their right to self-determination, thus sharing in the physician's choice regarding the medicament. The consent, though, could be considered implied by the acceptance of the switch or substitution on the part of the patient.

\section{Conclusions}

In the USA, the Food and Drug Administration has addressed the issue of interchangeability of biosimilars, by providing that interchangeability can be demonstrated [1] (though none of the approved biosimilars are deemed interchangeable) and the Administration is supporting a medical tort reform with the aim of "reducing the excessive burden the liability system places on the health care delivery system" [8]. In Europe, instead, the European Medicines Agency leaves the decision about interchangeability to individual member states [7], and the project of harmonising national tort legislations is still in its infancy [9].

In this framework of evolving legislation, sharing choices with patients and obtaining their informed consent when switching to a biosimilar could represent an effective approach on the part of the 
prescribing physician. Moreover, a supranational database containing real-life data about patients in treatment with biological medicines, including information on the actual biological medicinal products administered could complement existing clinical studies [10]. 


\section{References}

1. Biologics Price Competition and Innovation Act of 2009, Pub L No. 111-148, 124 Stat 806.

2. Minghetti P, Rocco P, Cilurzo F, Vecchio LD, Locatelli F. The regulatory framework of biosimilars in the European Union. Drug Discov Today. 2012; 17(1-2):63-70.

3. Restatement (Third) of Torts: Products Liability § 6(b) (Am. Law Inst. 1998)

4. Kesselheim AS, Green MD, Avorn J. Who Is Now Responsible for Discovering and Warning About Adverse Effects of Generic Drugs? JAMA. 2013; 310(10):1023-1024.

5. Jørgensen KK, Olsen IC, Goll GL, Lorentzen M, Bolstad N, Haavardsholm EA, Lundin KEA, Mørk C, Jahnsen J, Kvien TK; NOR-SWITCH study group. Switching from originator infliximab to biosimilar CT-P13 compared with maintained treatment with originator infliximab (NOR-SWITCH): a 52-week, randomised, double-blind, non-inferiority trial. Lancet. 2017; 389(10086):2304-2316.

6. Kurki P, van Aerts L, Wolff-Holz E, Giezen T, Skibeli V, Weise M. Interchangeability of Biosimilars: A European Perspective. BioDrugs. 2017; 31(2):83-91.

7. Minghetti P, Rocco P, Schellekens H. The constrained prescription, interchangeability and substitution of biosimilars. Nat Biotechnol 2015; 33(7):688-9.

8. Protecting Access to Care Act of 2017, H.R. 1215, 115th Cong. (2017). Available at: https://www.congress.gov/bill/ 115th-congress/house-bill/1215/text. Last checked on 07/03/2017.

9. European Group on Tort Law (EGTL). Principles of European Tort Law (2009). Available at http://www.egtl.org. Last checked on 07/03/2017.

10. Ebbers HC, Muenzberg M, Schellekens H. The safety of switching between therapeutic proteins. Expert Opin Biol Ther. 2012; 12(11):1473-85. 